\title{
A narrative review of the pathophysiology of ischemic stroke in carotid plaques: a distinction versus a compromise between hemodynamic and embolic mechanism
}

\author{
Laura Mechtouff ${ }^{1,2 \#}$, Lucie Rascle ${ }^{1 \#}$, Valentin Crespy $^{3}$, Emmanuelle Canet-Soulas $^{2}$, Norbert Nighoghossian ${ }^{1,2}$, \\ Antoine Millon ${ }^{3,4}$ \\ ${ }^{1}$ Stroke Center, Hospices Civils de Lyon, Lyon, France; ${ }^{2}$ INSERM U1060, CarMeN Laboratory, University Claude Bernard Lyon 1, Lyon, France; \\ ${ }^{3}$ Vascular Surgery Department, Hospices Civils de Lyon, Lyon, France; ${ }^{4}$ LIBM EA7424, Team Atherosclerosis, Thrombosis and Physical Activity, \\ University Claude Bernard Lyon 1, Lyon, France \\ Contributions: (I) Conception and design: None; (II) Administrative support: None; (III) Provision of study materials or patients: None; (IV) \\ Collection and assembly of data: None; (V) Data analysis and interpretation: None; (VI) Manuscript writing: All authors; (VII) Final approval of \\ manuscript: All authors. \\ \#These authors contributed equally to this work. \\ Correspondence to: Dr. Laura Mechtouff. Stroke Department, Hôpital Pierre Wertheimer, Hospices Civils de Lyon, 59 Boulevard Pinel 69677 Bron, \\ France. Email: laura.mechtouff@chu-lyon.fr.
}

\begin{abstract}
Atherosclerotic carotid artery stenosis causes about $10-20 \%$ of all ischemic strokes through two main mechanisms: hemodynamic impairment in case of significant stenosis and thromboembolism from an atherosclerotic plaque regardless of the degree of stenosis. The latter is the most frequent mechanism and appear to result from embolization from a vulnerable atherosclerotic plaque or acute occlusion of the carotid artery and propagation of thrombus distally. Downstream infarcts may occur in a territory of major cerebral artery or at the most distal areas between two territories of major cerebral arteries, the so-called watershed (WS), or border zone area. Although WS infarcts, especially deep WS infarct, were historically thought to be due to hemodynamic compromise, the role of microembolism has also been documented, both mechanisms may act synergistically to promote WS infarcts. Routine and more advanced imaging techniques may provide information on the underlying mechanism involved in ipsilateral ischemic stroke. A better understanding of ischemic stroke pathogenesis in carotid stenosis may limit the use of routine non-selective shunt, whose benefit-risk balance is debated, to patients with hemodynamic impairment.

After reviewing existing evidence underpinning the contribution of the two mechanisms in downstream ischemic stroke and the various imaging techniques available to investigate them, we will focus on the pathogenesis of WS infarcts that remains debated.
\end{abstract}

Keywords: Stroke; carotid stenosis; watershed infarct (WS infarct)

Submitted Nov 16, 2020. Accepted for publication May 31, 2021.

doi: $10.21037 /$ atm-20-7490

View this article at: https://dx.doi.org/10.21037/atm-20-7490

Prior studies have estimated that up to $20-25 \%$ of ischemic strokes are caused by large-artery atherosclerosis (1-3). Carotid artery disease is believed to be responsible for anywhere between 10 and $20 \%$ of ischemic stroke (4). The degree of stenosis is a relevant risk factor of ipsilateral ischemic stroke (5). This criterion has been used to select

$\wedge$ ORCID: 0000-0001-9165-5763. 
patients in randomized clinical trials and is consequently considered when making treatment decisions in patients with carotid disease $(6,7)$. However, the importance of hemodynamic factors in the pathogenesis of focal cerebral ischemia is still debated. While it is likely that some ischemic strokes associated with carotid artery disease result from hypoperfusion, the majority of such strokes appear to result from embolization from a vulnerable atherosclerotic plaque or acute occlusion of the carotid artery and propagation of thrombus distally (8-10). Routine and more advanced imaging techniques may provide information on the underlying mechanism involved in ipsilateral ischemic stroke (11-13). Downstream infarcts may affect watershed (WS) or border zone area, that are the most distal areas between two territories of major cerebral arteries (14). Some studies suggested that WS infarct, especially deep WS infarct, are related to hemodynamic compromise, but this hypothesis has been challenged by evidence on the contribution of microembolism in this setting (15). We aimed to review existing evidence and imaging modalities supporting the contribution of these two mechanisms, especially in the pathogenesis of WS infarcts, in which they may act synergistically.

We present the following article in accordance with the Narrative Review reporting checklist (available at https:// dx.doi.org/10.21037/atm-20-7490).

\section{Hemodynamic impairment downstream to carotid stenosis}

\section{Generalities about brain perfusion: cerebral autoregulation and vascular reserve}

The cerebral blood flow (CBF) is about $50 \mathrm{~mL} / 100 \mathrm{~g} /$ minutes (16-18). Cerebral autoregulation maintains a constant $\mathrm{CBF}$ in case of increased brain functional activity or a significant drop of systemic blood pressure (from 50 to $170 \mathrm{mmHg}$ ) (19). Cerebrovascular reserve is the ability of the brain to increase cerebral blood volume (CBV) via collateral network development to maintain a constant CBF. In case of severe decrease of CBF related to unilateral severe carotid artery stenosis, adaptative mechanisms are involved. First (grade I) a vasodilatation of arterioles occurs, which is traduced by an increase of mean transit time (MTT) and $\mathrm{CBV}$ while a normal oxygen extraction fraction (OEF) is maintained. If this mechanism is exhausted (grade II), OEF increases in order to maintain the cerebral metabolic rate of oxygen $\left(\mathrm{CMRO}_{2}\right)(20)$. At the end, when these compensatory mechanisms are exhausted and $\mathrm{CBF}$ and $\mathrm{CMRO}_{2}$ decreased, irreversible damage then takes place: this is ischemia (Figure 1) $(21,22)$.

Many different methods are available to evaluate brain perfusion: transcranial doppler (TCD), positron emission tomography (PET), xenon-CT (Xe-CT), singlephoton emission computed tomography (SPECT), CTangiography (CTA), MR-angiography (MRA), perfusion CT (CTP), MR perfusion (MRP) and conventional cerebral angiography $(16,23)$. PET is the gold standard to estimate cerebrovascular reserve. It uses an oxygen-15 radiotracer and can provide estimations of $\mathrm{CBV}, \mathrm{CBF}, \mathrm{CMRO}_{2}$ and MTT (21). TCD is used to evaluate vasomotor reactivity (VMR) in the middle cerebral artery (MCA) before and after the administration of either $\mathrm{CO}_{2}$ or acetazolamide. A reduced VMR is a marker of impaired cerebral perfusion and poor collateral circulation. SPECT also evaluates hemodynamic reserve by measuring regional VMR after administration of $\mathrm{CO}_{2}$ or acetazolamide. In physiological conditions, administration of acetazolamide increases blood flow by as much as $80 \%$. CT or MR perfusion-based methods are easily accessible in clinical practice and maps of CBF, CBV, MTT and time to peak (TTP) may be provided to estimate brain perfusion $(16,24)$.

\section{Evidence of hemodynamic impairment in case of carotid artery stenosis}

\section{Hemodynamic and cerebrovascular reactivity (CVR) studies}

Cerebral perfusion pressure is not systematically compromised downstream of carotid plaques. It is only in case of significant stenosis that brain hemodynamic may be impaired (25).

PET studies on patients with severe carotid stenosis show a decrease of $\mathrm{CBF}, \mathrm{CBF} / \mathrm{CBV}$ ratio, $\mathrm{CMRO}_{2}$ and an increase in MTT, CBV, and OEF in the ipsilateral hemisphere (26,27).

Many studies using acetazolamide (24) or $99 \mathrm{mTc}-$ HMPAO SPECT before and after injection of dipyridamole $(28,29)$ showed a reduced resting CBF and an altered CVR ipsilateral to the carotid stenosis after injection. More recently, multimodal MRI perfusion studies showed that $\mathrm{CBF}$ and CVR were decreased ipsilaterally to the stenosis (30). Lythgoe et al. found a significant increase in mean MTT and CBV, and a significant decrease in mean CBF ipsilateral MCA territory in carotid stenosis patients, compared with both the contralateral MCA territory 


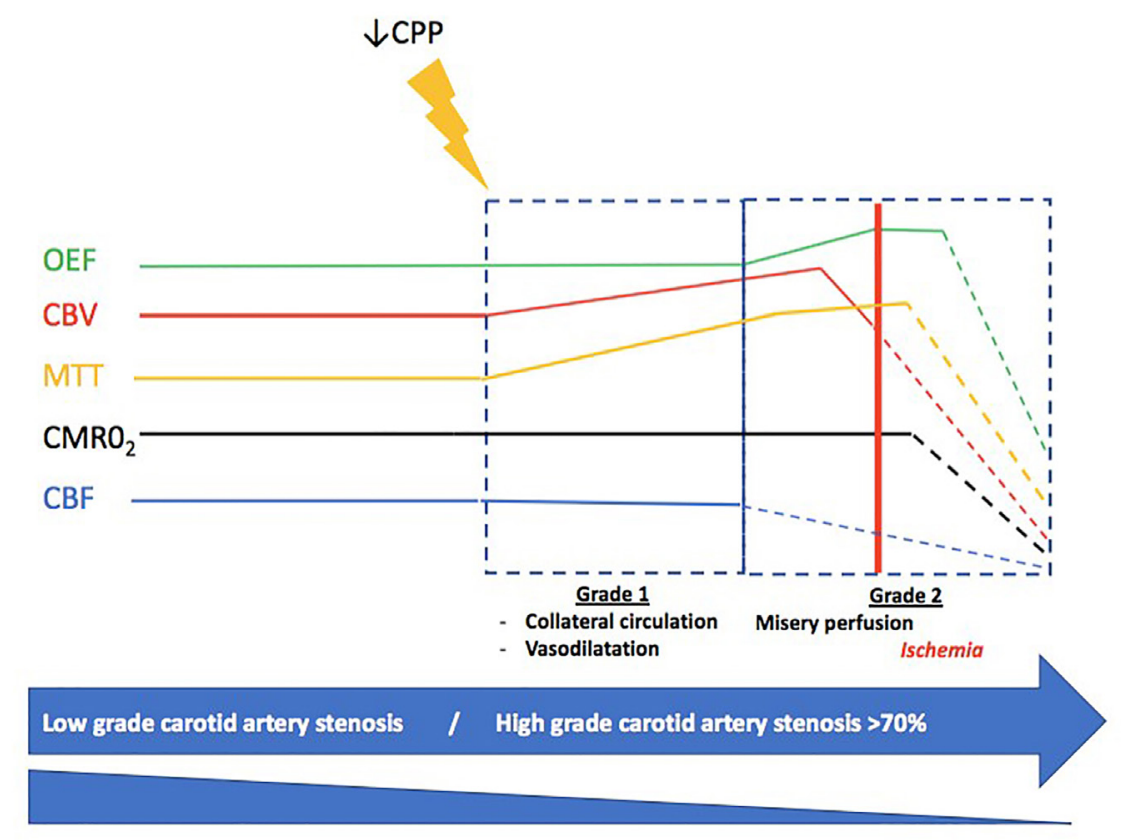

Figure 1 Illustration of cerebrovascular reserve in case of a CPP decrease due to high grade carotid artery stenosis. CPP, cerebral perfusion pressure; CBF, cerebral blood flow; CBV, cerebral blood volume; CMR02, cerebral metabolic rate of O2; MTT, mean transit time; OEF, oxygen extraction fraction.

and the control group (31). In a multimodal imaging study, CBF, mean flow velocity in MCA ipsilateral artery and VMR were significantly decreased in case of carotid stenosis (32). These results were confirmed by two other studies showing a decrease in CVR ipsilateral to carotid stenosis $(33,34)$. Finally a Xe/CT study found a decreased vasoreactivity to $\mathrm{C} 02$ in patients with carotid stenosis but no effect on CBF versus contralateral hemisphere (35).

An alteration of CVR, evaluated by apnea-induced hypercapnia and transcranial doppler was significantly associated with an increased risk of stroke in a prospective study (36). For Blaser et al. exhausted CVR was the major risk factor of stroke recurrence in case of symptomatic carotid stenosis (37). Webster et al. and Yonas et al. also showed in Xe-CT studies an association between a decreased CVR and risk of stroke in patients with severe carotid stenosis $(38,39)$. These results were corroborated by two other studies using CT perfusion and doppler ultrasound $(40,41)$. A meta-analysis has identified an increased OEF as an independent predictor of stroke in carotid stenosis or occlusion (42).

Moreover, many studies with different methods of brain perfusion or vasoreactivity evaluation showed an improvement of brain hemodynamic after endarterectomy or stenting (43-49).

These data suggest that hemodynamic impairment may play a role in the occurrence of stroke in patients with carotid stenosis.

\section{Influence of collateral circulation}

Some factors have been identified to explain patient susceptibility to ischemic stroke occurrence downstream to carotid stenosis. The most relevant protective factor seems to be the presence and the quality of collateral circulation. Collateral circulation is a compensatory pathway which can be recruited to preserve brain perfusion in case of acute or chronic hypoperfusion. Its protective role depends on several factors as anatomical variations, blood pressure, age and rate of development of steno-occlusive disease (16). Primary collateral pathways involved in carotid artery stenosis are represented by the circle of Willis. It is necessary to distinguish the anterior pathway with the anterior communicating artery and the $\mathrm{A} 1$ segment of the anterior cerebral artery (ACA) and the posterior communicating pathway with the posterior communicating artery and the P1 segment of the posterior cerebral artery (PCA). Secondary pathways are extra Willisian collaterals like retrograde flow via the external carotid and ophthalmic 
artery and leptomeningeal collateral flow via the PCA (50).

Fang et al. demonstrated that in patients with unilateral carotid stenosis, blood flow velocity in the contralateral commune carotid artery was higher than in the ipsilateral commune carotid artery (51). Furthermore, patients with bilateral carotid artery stenosis had higher blood flow velocity in vertebral arteries than control patients or patients with unilateral carotid artery stenosis. These data are in favor of compensatory mechanisms via collateral pathways in case of carotid stenosis. In a doppler study, CVR tended to be less important in patients without collateral circulation (52). There was a majority of patients with a reduced CVR ipsilateral to carotid stenosis.

These arguments highlight role of hemodynamic impairment in ischemic strokes downstream to carotid stenosis.

\section{Influence of degree of stenosis}

There is a relationship between the severity of symptomatic or asymptomatic carotid stenosis and the risk of ipsilateral ischemic stroke (53). Tomura et al. assessed the correlation between carotid stenosis degree and cerebral reserve alteration (54). They observed no significant association between $\mathrm{CBF}$ and stenosis degree but a small but significant association between CVR alteration and degree of stenosis. Jongen et al. showed that a higher degree of carotid artery stenosis was associated with a decreased CBF and an increased MTT (55). An association between doppler C02 vasoreactivity alteration and degree of stenosis was also reported but these results might be biased by the recruitment of patients who had experienced recent stroke or transient ischemic attack (TIA) (37).

\section{Microembolic mechanism from vulnerable carotid plaques}

Beyond the degree of stenosis and its potential hemodynamic impairment, carotid plaques, especially vulnerable plaques, cause mostly downstream ischemic stroke through a microembolic mechanism $(8,9)$.

This hypothesis is supported by data coming from TCD studies. TCD is a validated tool to detect cerebral microembolic signals (MES) using a probe placed in front of the ipsilateral middle cerebral artery (56). MES detection is predictive of ischemic stroke/TIA occurrence in patients with carotid stenosis both in asymptomatic (57) and symptomatic patients (58). A severe degree of carotid stenosis appears to be associated with a higher detection of
MES $(59,60)$, whereas optimizing medical treatment may decrease their detection (61).

Plaques that are more prone to cause distal embolization and subsequent TIA and stroke occurrence are qualified as vulnerable (62). Plaque features of vulnerability include a large lipid-rich necrotic core, a thin or ruptured fibrous cap, ulcerations and intraplaque hemorrhage and the presence of inflammatory cells (63). Several approaches have been developed to identify imaging markers of plaque vulnerability from routine to advanced techniques, using ultrasound, CTA, MRI or other imaging techniques (Figure 2) $(11,12)$. Carotid stenosis progression is also considered as a marker of vulnerability (64). The prevalence of vulnerable plaques on the basis of various imaging criteria account for about $25 \%$ of all asymptomatic carotid plaques (65). Plaques classified as vulnerable were associated with a higher risk of an ipsilateral ischemic event (65). This relationship was also observed in case of $<50 \%$ luminal narrowing plaques among patients with cryptogenic stroke (66) and, more specifically those with embolic stroke of undetermined source (67).

Among routine imaging, two-dimensional ultrasound is often used as first-line imaging and provide information on carotid plaque echostructure, besides the degree of stenosis. Echolucency that corresponds to lipid-rich necrotic core or intraplaque hemorrhage has been established as a stroke risk marker (68-70) as well as higher juxta-luminal hypoechoic black size $(71,72)$ and plaque area $(72)$. Other risk markers as ulceration (73) and neovascularization $(74,75)$ may be assessed using three-dimensional and contrast-enhanced ultrasound.

CTA, which is widely available, may approach plaque vulnerability with a high degree of agreement with histologic examination (76) and high-resolution MRI (77). Soft plaque, plaque ulceration, increased common carotid artery wall thickness and lack of calcifications on CTA have been associated with the risk of ipsilateral stroke (78).

Advanced imaging as high resolution MRI and PET/ CT or PET/MRI studies of carotid plaques now offer the possibility to better characterize plaque composition and risk features (12). High resolution MRI is an accurate, sensitive and specific method for determining the plaque characteristics of vulnerability, as the lipid rich necrotic core, thin and/or ruptured fibrous cap and intraplaque hemorrhage compared to histological findings $(79,80)$. High resolution contrast-enhanced MRI can also detect increased plaque permeability, a hallmark of neoangiogenesis (81). The inflammatory plaque component was mainly evaluated 
A

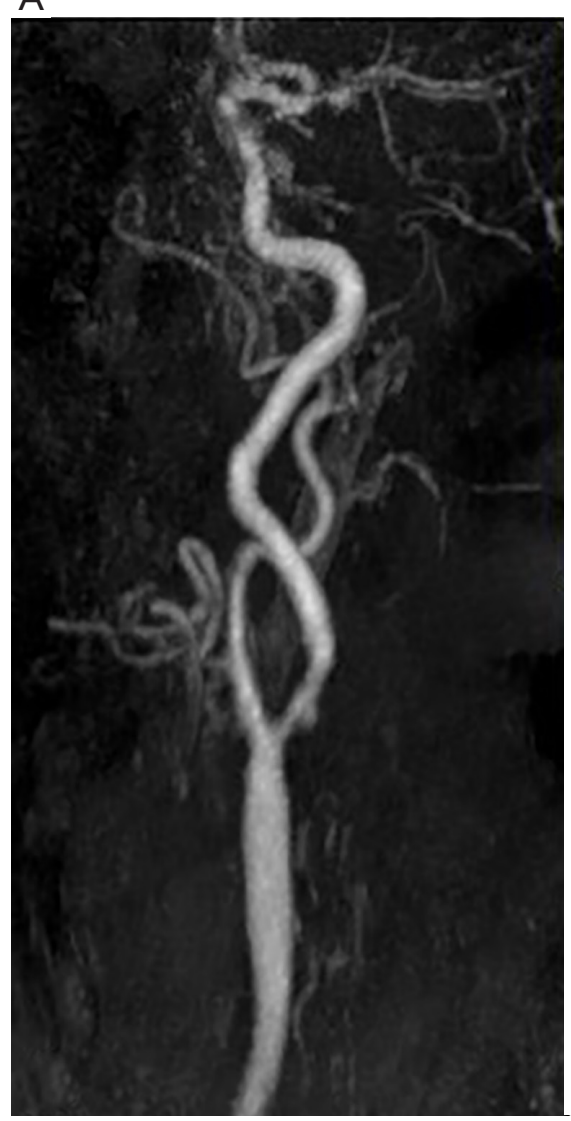

B

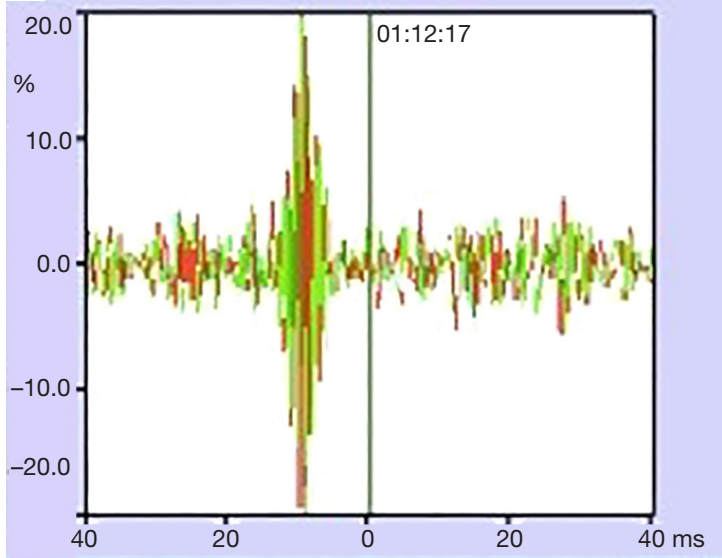

C

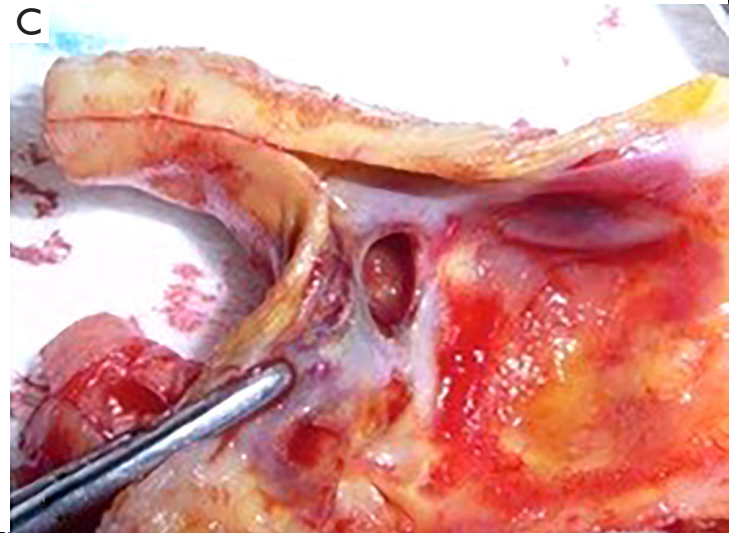

Figure 2 Illustrative case of a 73-year-old woman with a transient ischemic attack. Angio-MR MIP (maximum intensity projection) reconstruction (A) highlighting the presence of a plaque ulceration of the right internal carotid artery (image courtesy of Sara Boccalini). Transcranial Doppler (B) showing a cerebral microembolic signal in the right middle cerebral artery. Surgical specimen confirming the presence of ulceration $(\mathrm{C})$.

with 18F-fluorodeoxyglucose (FDG) PET/CT (82). Indeed, FDG uptake has been recognized as a marker of stroke risk and correlated with MES (83). Inflammation imaging of atherosclerosis is an active research field and new tracers are currently under clinical evaluation using hybrid imaging, PET/CT or PET/MRI (84). Among the other factors of plaque vulnerability, intraplaque neoangiogenesis and hypoxia are associated with an increased risk. Hypoxia can be evaluated by $18 \mathrm{~F}$-fluoromisonidazole (FMISO) PET and was correlated with FDG uptake (85). Thus, FDG PET/MRI can explore the link between MRI vulnerable plaque features and inflammation (84). In a small study of 18 patients using 18F-FDG PET/MRI, non-stenotic carotid plaques were diagnosed as the cause of embolic stroke of unknown origin (86). Microcalcification is the hallmark of active atherosclerosis and is linked to acute events. It can be evaluated by PET/CT or PET/MRI using $18 \mathrm{~F}$-sodium fluoride $(\mathrm{NaF})$ (87). Two recent studies used both $\mathrm{NaF}$ and FDG PET tracers to evaluate the association of active microcalcification and inflammation in culprit plaques $(88,89)$. The study by Fujimoto $e t$ al. conducted in 28 patients assessed the relationship between these tracers and the severity of ischemic brain disease on MRI and concluded that $\mathrm{NaF}$ uptake appeared more discriminant than FDG (89).

\section{WS infarct pattern}

In 1959, German neurosurgeons Wilhelm Tönnis and Wolfgang Schiefer endorsed the Schneider's concept of "letzte Wiese" to explain the manifestation of circulatory disturbances in the border zones between the 3 large 

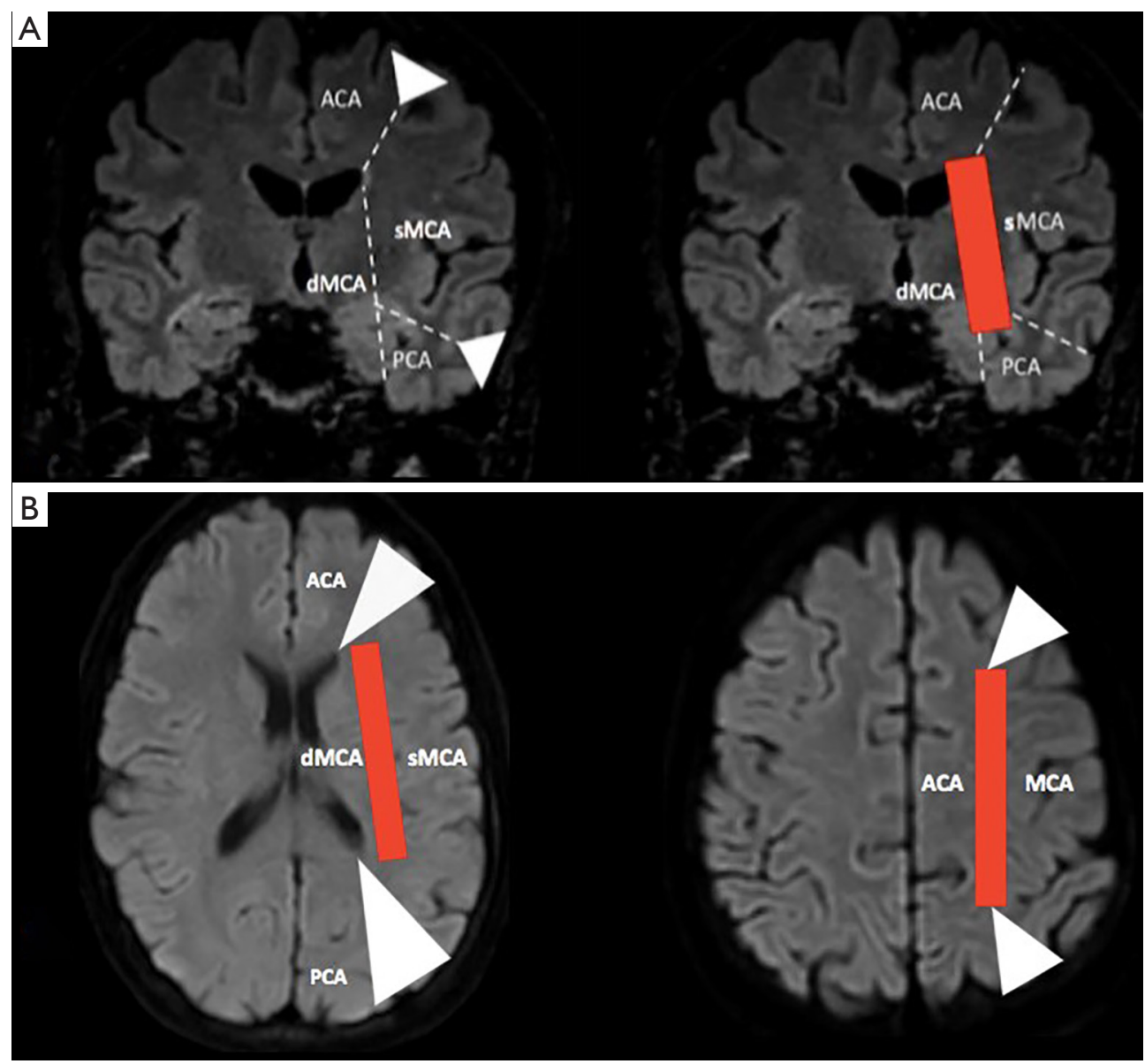

Figure 3 Schematic representation of watershed area. Coronal (A) and axial (B) representation of cortical (white) and internal (red) watershed area. ACA, anterior cerebral artery; MCA, middle cerebral artery; dMCA, deep MCA; sMCA, superficial MCA; PCA, posterior cerebral artery.

cerebral arteries and in basal ganglia and internal capsule (90).

WS or border zones correspond to the most distal areas between two territories of major cerebral arteries $(14,15)$. Cortical WS zones are located between the cortical territories of the ACA, MCA, and PCA. Deep or internal WS zones are located in the white matter along and slightly above the lateral ventricle, between the superficial systems of the MCA and ACA, or between the deep and the superficial arterial systems of the MCA (Figures 3 and 4) (91). Deep WS zones are divided into confluent and partial infarcts either as a single lesion or in "rosary-like" pattern in the centrum semiovale. However, WS zones and vascular territories have variable spatial distribution in healthy individuals $(92,93)$ and even more markedly in those with artery stenosis or occlusion (94) in whom collateral pathways is recruited in a highly individual pattern to compensate for diminished blood flow. An individual WS zone mapping using multimodal MRI has been proposed to take into account this inter-individual spatial variability $(95,96)$.

WS, or border-zone, infarcts account for about $10 \%$ of all infarcts and for up to about $60 \%$ of infarcts in patients with carotid artery stenosis or occlusion (97-101). The pathogenesis of WS infarcts remains debated. WS infarcts, and particularly deep WS and the rosary-like pattern, were historically thought to be due to hemodynamic compromise in the setting of carotid artery stenosis or occlusion as supplying by distal arterial branches with lowest perfusion pressure (102). Indeed, they were observed early in the clinical setting of severe systemic hypotension $(2,103,104)$. Several PET, SPECT, MRI and TCD sonography 

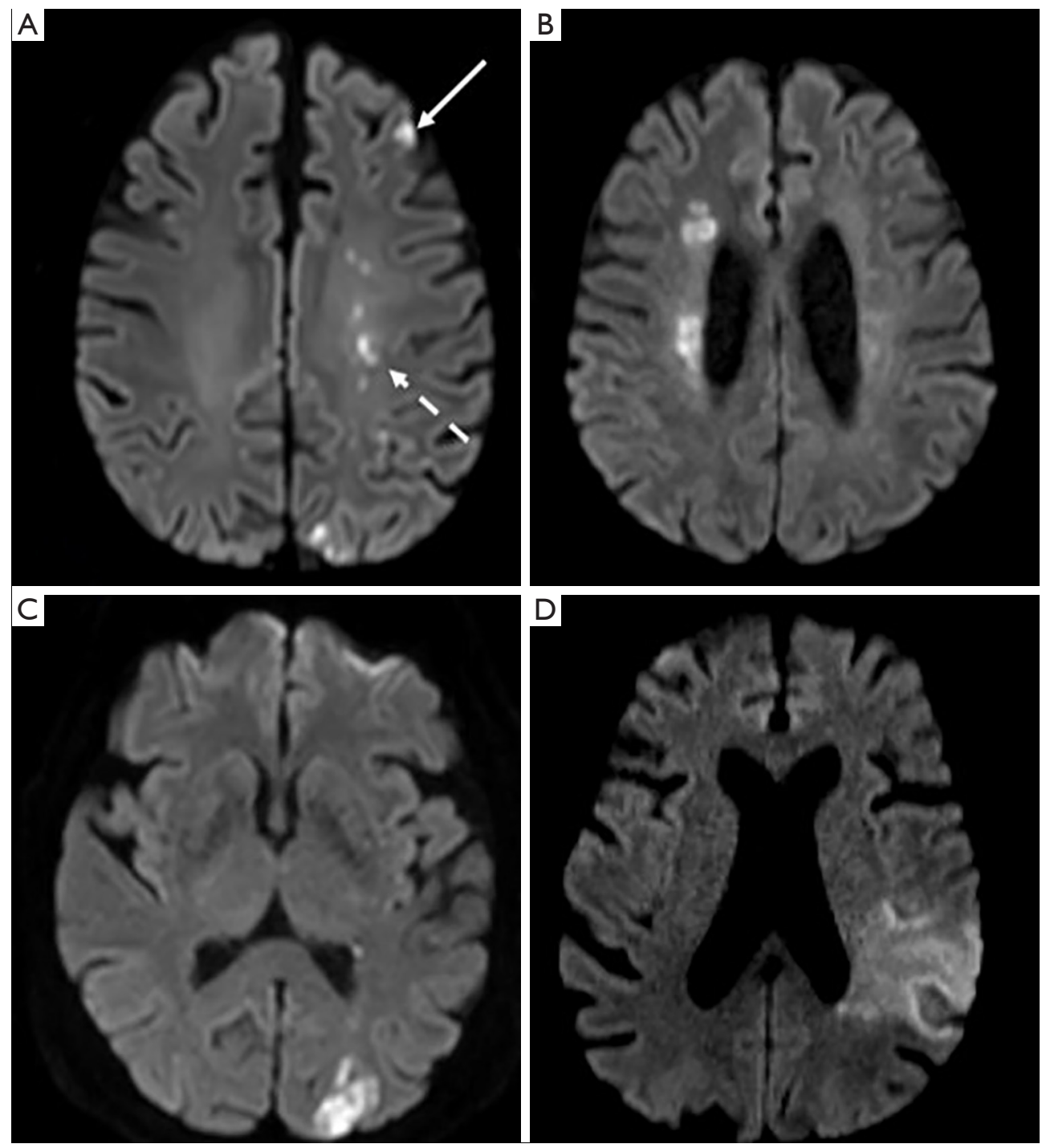

Figure 4 Axial slices of diffusion-weighted MRI showing anterior cortical (full arrow) and internal (dotted arrow) watershed infarcts (A), internal (full arrow) watershed infarcts (B), posterior cortical watershed infarcts (C) and a territorial infarct in the middle cerebral artery territory $(\mathrm{D})$.

studies have demonstrated hemodynamic impairment in these zones as reduced regional $\mathrm{CBF}$, reduced perfusion reserve, and an elevated regional OEF (13,105-107). The relationship between a noncompetent circle of Willis (108-110) or a reduced MCA intensity on 3D TOF MRA (111) and WS infarcts, in particular in deep WS infarcts, also argued for this hypothesis. The supposedly stronger role of hemodynamic impairment in deep WS infarcts was reinforced by the fact that deep WS infarcts had more likely a higher degree of stenosis or occlusion in either the middle cerebral or internal carotid artery (101) and were mainly due to large artery atherosclerosis (112) than cortical WS infarcts.

However, evidence of the role of embolism in the pathophysiology of WS infarcts has been documented early in autopsy studies showing the presence of microemboli including cholesterol crystals in arteries supplying WS zones (98,113-116). In addition, the perfusion with suspensions of glass microspheres of the brains of cadavers resulted in distribution of these microspheres into the WS zones as well as various arterial territories (117). The preferential distribution pattern of the microspheres into 
the WS zones was affected by their diameters, as observed in rodents (118). An experimental study conducted in nonhuman primates showed that subsequent WS infarcts affected both cortical and deep WS zones (119). In a clinical study, ipsilateral MES were common in patients with recent WS infarct related to carotid artery stenosis or occlusion thus demonstrating an embolic mechanism from the plaque (120). In the same way, carotid intraplaque hemorrhage, a marker of plaque instability, tended to be associated with WS infarcts in the absence of severe hemodynamic impairment (121). Emboli may also come upstream from the carotid artery. Thus, cardioembolism was considered as the most frequent cause of cortical WS infarcts and accounted for about $15 \%$ of deep WS infarcts (112).

A dichotomized approach is nevertheless likely too simplistic. Caplan et al. proposed that hemodynamic compromise and embolism may be intimately intertwined. Thus, reduced perfusion may hamper washout or clearance of emboli, particularly within the WS zone or make this brain area, with marginal perfusion, more vulnerable to the effect of microemboli (122). In any case, these two mechanisms appear to contribute, solely or synergistically, to all subtypes of deep WS infarcts according to studies combining brain perfusion mapping and MES assessment in patients with recently symptomatic carotid stenosis $(83,123)$.

\section{Conclusions}

While some ischemic strokes associated with carotid artery disease may result from hypoperfusion, most of them are related to embolism from a vulnerable plaque. The contribution of these different pathways in patients with carotid plaque cannot be inferred from infarct pattern but may be explored using routine and more advanced imaging techniques. A better understanding of ischemic stroke pathogenesis in carotid stenosis may limit the use of routine non-selective shunt, whose benefit-risk balance is debated, to patients with hemodynamic impairment (124).

\section{Acknowledgments}

We thank Michelle Grange for proofreading the English and Marc Hermier and Sara Boccalini for their contribution. RHU MARVELOUS (ANR-16-RHUS-0009) of Université Claude Bernard Lyon-1 (UCBL), within the program "Investissements d'Avenir" operated by the French National Research Agency (ANR).
Funding: None.

\section{Footnote}

Provenance and Peer Review: This article was commissioned by the Guest Editor (Kosmas I. Paraskevas) for the series "Carotid Artery Stenosis and Stroke-Prevention and Treatment Part II" published in Annals of Translational Medicine. The article has undergone external peer review.

Reporting Checklist: The authors have completed the Narrative Review reporting checklist. Available at https:// dx.doi.org/10.21037/atm-20-7490

Peer Review File: Available at https://dx.doi.org/10.21037/ atm-20-7490

Conflicts of Interest: All authors have completed the ICMJE uniform disclosure form (available at https://dx.doi. org/10.21037/atm-20-7490). The series "Carotid Artery Stenosis and Stroke-Prevention and Treatment Part II" was commissioned by the editorial office without any funding or sponsorship. The authors have no other conflicts of interest to declare.

Ethical Statement: The authors are accountable for all aspects of the work in ensuring that questions related to the accuracy or integrity of any part of the work are appropriately investigated and resolved.

Open Access Statement: This is an Open Access article distributed in accordance with the Creative Commons Attribution-NonCommercial-NoDerivs 4.0 International License (CC BY-NC-ND 4.0), which permits the noncommercial replication and distribution of the article with the strict proviso that no changes or edits are made and the original work is properly cited (including links to both the formal publication through the relevant DOI and the license). See: https://creativecommons.org/licenses/by-nc-nd/4.0/.

\section{References}

1. Petty GW, Brown RD, Whisnant JP, et al. Ischemic Stroke Subtypes: A Population-Based Study of Incidence and Risk Factors. Stroke 1999;30:2513-6.

2. Adams JH, Brierley JB, Connor RCR, et al. The effects of systemic hypotension upon the human brain. Clinical and neuropathological observations in 11 cases. Brain 
1966;89:235-68.

3. Ornello R, Degan D, Tiseo C, et al. Distribution and Temporal Trends From 1993 to 2015 of Ischemic Stroke Subtypes: A Systematic Review and Meta-Analysis. Stroke 2018;49:814-9.

4. Barrett KM, Brott TG. Stroke Caused by Extracranial Disease. Circ Res 2017;120:496-501.

5. Nicolaides AN, Kakkos SK, Griffin M, et al. Severity of Asymptomatic Carotid Stenosis and Risk of Ipsilateral Hemispheric Ischaemic Events: Results from the ACSRS Study. Eur J Vasc Endovasc Surg 2005;30:275-84.

6. Naylor AR, Ricco J-B, de Borst GJ, et al. Editor's Choice - Management of Atherosclerotic Carotid and Vertebral Artery Disease: 2017 Clinical Practice Guidelines of the European Society for Vascular Surgery (ESVS). Eur J Vasc Endovasc Surg 2018;55:3-81.

7. Brott TG, Halperin JL, Abbara S, et al. 2011 ASA/ACCF/ AHA/AANN/AANS/ACR/ASNR/CNS/SAIP/SCAI/ SIR/SNIS/SVM/SVS Guideline on the Management of Patients With Extracranial Carotid and Vertebral Artery Disease: Executive Summary: A Report of the American College of Cardiology Foundation/American Heart Association Task Force on Practice Guidelines, and the American Stroke Association, American Association of Neuroscience Nurses, American Association of Neurological Surgeons, American College of Radiology, American Society of Neuroradiology, Congress of Neurological Surgeons, Society of Atherosclerosis Imaging and Prevention, Society for Cardiovascular Angiography and Interventions, Society of Interventional Radiology, Society of NeuroInterventional Surgery, Society for Vascular Medicine, and Society for Vascular Surgery. Circulation 2011;124:489-532.

8. Pessin MS, Hinton RC, Davis KR, et al. Mechanisms of acute carotid stroke. Ann Neurol 1979;6:245-52.

9. Golledge J, Greenhalgh RM, Davies AH. The Symptomatic Carotid Plaque. Stroke 2000;31:774-81.

10. Ringelstein EB, Sievers C, Ecker S, et al. Noninvasive assessment of $\mathrm{CO} 2$-induced cerebral vasomotor response in normal individuals and patients with internal carotid artery occlusions. Stroke 1988;19:963-9.

11. Nighoghossian N, Derex L, Douek P. The Vulnerable Carotid Artery Plaque: Current Imaging Methods and New Perspectives. Stroke 2005;36:2764-72.

12. Fabiani I, Palombo C, Caramella D, et al. Imaging of the vulnerable carotid plaque: Role of imaging techniques and a research agenda. Neurology 2020;94:922-32.

13. Momjian-Mayor I, Baron JC. The Pathophysiology of Watershed Infarction in Internal Carotid Artery Disease: Review of Cerebral Perfusion Studies. Stroke 2005;36:567-77.

14. Zülch KJ. Über die Entstehung und Lokalisation der Hirninfarkte. Acta Neurol Chir 1961;7:1-117.

15. Hossmann KA, Heiss WD. History of the Letzte Wiese/Last Meadow Concept of Brain Ischemia. Stroke 2016;47:e46-50.

16. Romero JR, Pikula A, Nguyen TN, et al. Cerebral Collateral Circulation in Carotid Artery Disease. Curr Cardiol Rev 2009;5:279-88.

17. Vavilala MS, Lee LA, Lam AM. Cerebral blood flow and vascular physiology. Anesthesiol Clin North Am 2002;20:247-64.

18. Puig O, Henriksen OM, Vestergaard MB, et al. Comparison of simultaneous arterial spin labeling MRI and 15 O-H 2 O PET measurements of regional cerebral blood flow in rest and altered perfusion states. J Cereb Blood Flow Metab 2020;40:1621-33.

19. Castro P, Azevedo E, Sorond F. Cerebral Autoregulation in Stroke. Curr Atheroscler Rep 2018;20:37.

20. Derdeyn CP, Videen TO, Yundt KD, et al. Variability of cerebral blood volume and oxygen extraction: stages of cerebral haemodynamic impairment revisited. Brain 2002;125:595-607.

21. Tsivgoulis G, Alexandrov AV. Cerebral Hemodynamics in Acute Stroke: Pathophysiology and Clinical Implications. J Vasc Interv Neurol 2008;1:65-9.

22. Baron JC, Jones T. Oxygen metabolism, oxygen extraction and positron emission tomography: Historical perspective and impact on basic and clinical neuroscience. NeuroImage 2012;61:492-504.

23. Griffiths PD, Hoggard N, Dannels WR, et al. In vivo measurement of cerebral blood flow: a review of methods and applications. Vasc Med 2001;6:51-60.

24. Cikrit DF, Dalsing MC, Lalka SG, et al. The value of acetazolamide single photon emission computed tomography scans in the preoperative evaluation of asymptomatic critical carotid stenosis. J Vasc Surg 1999;30:599-605.

25. Schroeder T. Hemodynamic significance of internal carotid artery disease. Acta Neurologica Scandinavica 1988;77:353-72.

26. Duncan DB, Fink GR, Wirth M, et al. Heterogeneity of Cerebral Hemodynamics and Metabolism in Carotid Artery Disease. J Nucl Med 1996;37:429-32.

27. Hino A, Tenjin H, Horikawa $Y$, et al. Hemodynamic and Metabolic Changes After Carotid Endarterectomy in 
Patients With High-Degree Carotid Artery Stenosis. J

Stroke Cerebrovasc Dis 2005;14:234-8.

28. Garai I, Varga J, Szomják E, et al. Quantitative assessment of blood flow reserve using 99m Tc-HMPAO in carotid stenosis. Eur J Nucl Med Mol Imaging 2002;29:216-20.

29. Hwang T-L, Saenz A, Farrell JJ, et al. Brain SPECT with Dipyridamole Stress to Evaluate Cerebral Blood Flow Reserve in Carotid Artery Disease. J Nucl Med 1996;37:1595-9.

30. Bullock R, Mendelow AD, Patterson J, et al. Cerebral blood flow and $\mathrm{CO} 2$ responsiveness as an indicator of collateral reserve capacity in patients with carotid arterial disease. Br J Surg 1985;72:348-51.

31. Lythgoe DJ, Østergaard L, Williams SCR, et al. Quantitative perfusion imaging in carotid artery stenosis using dynamic susceptibility contrast-enhanced magnetic resonance imaging. Magn Reson Imaging 2000;18:1-11.

32. Marshall RS, Pavol MA, Cheung YK, et al. Dissociation among hemodynamic measures in asymptomatic high grade carotid artery stenosis. J Neurol Sci 2016;367:143-7.

33. Hetzel A, Guschlbauer B, Reinhard M. Time Delay as a Parameter for Cerebrovascular Reactivity in Patients with Severe Carotid Stenosis. Cerebrovasc Dis 2003;16:14-20.

34. Chimowitz MI, Furlan AJ, Jones SC, et al. Transcranial Doppler assessment of cerebral perfusion reserve in patients with carotid occlusive disease and no evidence of cerebral infarction. Neurology 1993;43:353.

35. Bullock R, Mendelow AD, Patterson J, et al. Cerebral blood flow measurement as an indicator of the haemodynamic severity of carotid artery disease in man. S Afr Med J 1984;65:429-31.

36. Silvestrini M, Vernieri F, Pasqualetti P, et al. Impaired Cerebral Vasoreactivity and Risk of Stroke in Patients With Asymptomatic Carotid Artery Stenosis. JAMA 2000;283:2122-7.

37. Blaser T, Hofmann K, Buerger T, et al. Risk of Stroke, Transient Ischemic Attack, and Vessel Occlusion Before Endarterectomy in Patients With Symptomatic Severe Carotid Stenosis. Stroke 2002;33:1057-62.

38. Yonas H, Smith HA, Durham SR, et al. Increased stroke risk predicted by compromised cerebral blood flow reactivity. J Neurosurg 1993;79:483-9.

39. Webster MW, Makaroun MS, Steed DL, et al. Compromised cerebral blood flow reactivity is a predictor of stroke in patients with symptomatic carotid artery occlusive disease. J Vasc Surg 1995;21:338-44.

40. Markus H. Severely impaired cerebrovascular reactivity predicts stroke and TIA risk in patients with carotid artery stenosis and occlusion. Brain 2001;124:457-67.

41. Liu S, Cai J, Ge F, et al. The risk of ischemic events increased in patients with asymptomatic carotid stenosis with decreased cerebrovascular reserve. J Investig Med 2017;65:1028-32.

42. Gupta A, Baradaran H, Schweitzer AD, et al. Oxygen Extraction Fraction and Stroke Risk in Patients with Carotid Stenosis or Occlusion: A Systematic Review and Meta-Analysis. Am J Neuroradiol 2014;35:250-5.

43. Sfyroeras G, Karkos CD, Liasidis C, et al. The impact of carotid stenting on the hemodynamic parameters and cerebrovascular reactivity of the ipsilateral middle cerebral artery. J Vasc Surg 2006;44:1016-22.

44. Ostrý S, Stejskal L, Kramár F, et al. Hypercapnia Impact on Vascular and Neuronal Reactivity in Patients Before and After Carotid Endarterectomy. Zentralbl Neurochir 2007;68:59-66.

45. Tang SC, Huang YW, Shieh JS, et al. Dynamic cerebral autoregulation in carotid stenosis before and after carotid stenting. J Vasc Surg 2008;48:88-92.

46. Teng MMH, Chang FC, Lin CJ, et al. Peritherapeutic Hemodynamic Changes of Carotid Stenting Evaluated with Quantitative DSA in Patients with Carotid Stenosis. AJNR Am J Neuroradiol 2016;37:1883-8.

47. Wang J, Wang W, Jin B, et al. Improvement in Cerebral and Ocular Hemodynamics Early after Carotid Endarterectomy in Patients of Severe Carotid Artery Stenosis with or without Contralateral Carotid Occlusion. BioMed Res Int 2016;2016:2901028.

48. Merckel LG, Van der Heijden J, Jongen LM, et al. Effect of Stenting on Cerebral CT Perfusion in Symptomatic and Asymptomatic Patients with Carotid Artery Stenosis. AJNR Am J Neuroradiol 2012;33:280-5.

49. Gauvrit JY, Delmaire C, Henon H, et al. Diffusion/ perfusion-weighted magnetic resonance imaging after carotid angioplasty and stenting. J Neurol 2004;251:1060-7.

50. Reinhard M, Müller T, Guschlbauer B, et al. Dynamic cerebral autoregulation and collateral flow patterns in patients with severe carotid stenosis or occlusion. Ultrasound Med Biol 2003;29:1105-13.

51. Fang H, Song B, Cheng B, et al. Compensatory patterns of collateral flow in stroke patients with unilateral and bilateral carotid stenosis. BMC Neurol 2016;16:39.

52. Palacios-Mendoza MA, García-Pastor A, et al. Ultrasonographic and hemodynamic characteristics of patients with symptomatic carotid near-occlusion: results from a multicenter registry study. Neuroradiology 
2021;63:705-11.

53. Touzé E. Natural history of asymptomatic carotid artery stenosis. Revue Neurologique 2008;164:793-800.

54. Tomura N, Otani T, Koga M, et al. Correlation Between Severity of Carotid Stenosis and Vascular Reserve Measured by Acetazolamide Brain Perfusion Single Photon Emission Computed Tomography. J Stroke Cerebrovasc Dis 2013;22:166-70.

55. Jongen LM, van der Worp HB, Waaijer A, et al. Interrelation between the Degree of Carotid Stenosis, Collateral Circulation and Cerebral Perfusion. Cerebrovasc Dis 2010;30:277-84.

56. Markus HS, Brown MM. Differentiation between different pathological cerebral embolic materials using transcranial Doppler in an in vitro model. Stroke 1993;24:1-5.

57. Spence JD, Tamayo A, Lownie SP, et al. Absence of microemboli on transcranial Doppler identifies lowrisk patients with asymptomatic carotid stenosis. Stroke 2005;36:2373-8.

58. Markus HS, MacKinnon A. Asymptomatic embolization detected by Doppler ultrasound predicts stroke risk in symptomatic carotid artery stenosis. Stroke 2005;36:971-5.

59. Altaf N, Goode SD, Beech A, et al. Plaque Hemorrhage Is a Marker of Thromboembolic Activity in Patients with Symptomatic Carotid Disease. Radiology 2011;258:538-45.

60. Jayasooriya G, Thapar A, Shalhoub J, et al. Silent cerebral events in asymptomatic carotid stenosis. J Vasc Surg 2011;54:227-36.

61. Spence JD. Effects of Intensive Medical Therapy on Microemboli and Cardiovascular Risk in Asymptomatic Carotid Stenosis. Arch Neurol 2010;67:180.

62. Naghavi M, Libby P, Falk E, et al. From Vulnerable Plaque to Vulnerable Patient: A Call for New Definitions and Risk Assessment Strategies: Part I. Circulation 2003;108:1664-72.

63. Stary HC, Chandler AB, Dinsmore RE, et al. A Definition of Advanced Types of Atherosclerotic Lesions and a Histological Classification of Atherosclerosis: A Report From the Committee on Vascular Lesions of the Council on Arteriosclerosis, American Heart Association. Circulation 1995;92:1355-74.

64. Kakkos SK, Nicolaides AN, Charalambous I, et al. Predictors and clinical significance of progression or regression of asymptomatic carotid stenosis. J Vasc Surg 2014;59:956-967.e1.

65. Kamtchum-Tatuene J, Noubiap JJ, Wilman AH, et al. Prevalence of High-Risk Plaques and Risk of Stroke in
Patients With Asymptomatic Carotid Stenosis: A Metaanalysis. JAMA Neurol 2020;77:1524-35.

66. Freilinger TM, Schindler A, Schmidt C, et al. Prevalence of Nonstenosing, Complicated Atherosclerotic Plaques in Cryptogenic Stroke. JACC Cardiovasc Imaging 2012;5:397-405.

67. Kamtchum-Tatuene J, Wilman A, Saqqur M, et al. Carotid Plaque With High-Risk Features in Embolic Stroke of Undetermined Source: Systematic Review and MetaAnalysis. Stroke 2020;51:311-4.

68. Gupta A, Kesavabhotla K, Baradaran H, et al. Plaque Echolucency and Stroke Risk in Asymptomatic Carotid Stenosis: A Systematic Review and Meta-Analysis. Stroke 2015;46:91-97.

69. Geroulakos G, Ramaswami G, Nicolaides A, et al. Characterization of symptomatic and asymptomatic carotid plaques using high-resolution real-time ultrasonography. Br J Surg 1993;80:1274-77.

70. El-Barghouty NM, Levine T, Ladva S, et al. Histological verification of computerised carotid plaque characterisation. Eur J Vasc Endovasc Surg 1996;11:414-6.

71. Kakkos SK, Griffin MB, Nicolaides AN, et al. The size of juxtaluminal hypoechoic area in ultrasound images of asymptomatic carotid plaques predicts the occurrence of stroke. J Vasc Surg 2013;57:609-618.e1.

72. Salem MK, Bown MJ, Sayers RD, et al. Identification of Patients with a Histologically Unstable Carotid Plaque Using Ultrasonic Plaque Image Analysis. Eur J Vasc Endovasc Surg 2014;48:118-25.

73. Schminke U, Motsch L, Hilker L, et al. ThreeDimensional Ultrasound Observation of Carotid Artery Plaque Ulceration. Stroke 2000;31:1651-5.

74. Huang R, Abdelmoneim SS, Ball CA, et al. Detection of Carotid Atherosclerotic Plaque Neovascularization Using Contrast Enhanced Ultrasound: A Systematic Review and Meta-Analysis of Diagnostic Accuracy Studies. J Am Soc Echocardiogr 2016;29:491-502.

75. Lyu Q, Tian X, Ding Y, et al. Evaluation of Carotid Plaque Rupture and Neovascularization by Contrast-Enhanced Ultrasound Imaging: an Exploratory Study Based on Histopathology. Transl Stroke Res 2021;12:49-56.

76. Wintermark M, Jawadi SS, Rapp JH, et al. HighResolution CT Imaging of Carotid Artery Atherosclerotic Plaques. AJNR Am J Neuroradiol 2008;29:875-82.

77. Trelles M, Eberhardt KM, Buchholz M, et al. CTA for Screening of Complicated Atherosclerotic Carotid Plaque-American Heart Association Type VI Lesions as Defined by MRI. AJNR Am J Neuroradiol 
2013;34:2331-7.

78. Baradaran H, Al-Dasuqi K, Knight-Greenfield A, et al. Association between Carotid Plaque Features on CTA and Cerebrovascular Ischemia: A Systematic Review and MetaAnalysis. AJNR Am J Neuroradiol 2017;38:2321-6.

79. den Hartog AG, Bovens SM, Koning W, et al. Current Status of Clinical Magnetic Resonance Imaging for Plaque Characterisation in Patients with Carotid Artery Stenosis. Eur J Vasc Endovasc Surg 2013;45:7-21.

80. Serfaty J-M, Chaabane L, Tabib A, et al. Atherosclerotic Plaques: Classification and Characterization with T2weighted High-Spatial-Resolution MR Imaging-An in Vitro Study. Radiology 2001;219:403-10.

81. Qiao Y, Etesami M, Astor BC, et al. Carotid Plaque Neovascularization and Hemorrhage Detected by MR Imaging are Associated with Recent Cerebrovascular Ischemic Events. AJNR Am J Neuroradiol 2012;33:755-60.

82. Evans NR, Tarkin JM, Buscombe JR, et al. PET imaging of the neurovascular interface in cerebrovascular disease. Nat Rev Neurol 2017;13:676-88.

83. Moustafa RR, Izquierdo-Garcia D, Jones PS, et al. Watershed Infarcts in Transient Ischemic Attack/Minor Stroke With $\geq 50 \%$ Carotid Stenosis: Hemodynamic or Embolic? Stroke 2010;41:1410-6.

84. Evans NR, Tarkin JM, Le EP, et al. Integrated cardiovascular assessment of atherosclerosis using PET/ MRI. BJR 2020;93:20190921.

85. Joshi FR, Manavaki R, Fryer TD, et al. Vascular Imaging With 18 F-Fluorodeoxyglucose Positron Emission Tomography Is Influenced by Hypoxia. J Am Coll Cardiol 2017;69:1873-4.

86. Hyafil F, Schindler A, Sepp D, et al. High-risk plaque features can be detected in non-stenotic carotid plaques of patients with ischaemic stroke classified as cryptogenic using combined 18F-FDG PET/MR imaging. Eur J Nucl Med Mol Imaging 2016;43:270-9.

87. Mechtouff L, Sigovan M, Douek P, et al. Simultaneous assessment of microcalcifications and morphological criteria of vulnerability in carotid artery plaque using hybrid 18F-NaF PET/MRI. J Nucl Cardiol 2020. [Epub ahead of print].

88. Evans NR, Tarkin JM, Chowdhury MM, et al. DualTracer Positron-Emission Tomography for Identification of Culprit Carotid Plaques and Pathophysiology In Vivo. Circ Cardiovasc Imaging 2020;13:e009539.

89. Fujimoto K, Norikane T, Yamamoto Y, et al. Association between carotid $18 \mathrm{~F}-\mathrm{NaF}$ and $18 \mathrm{~F}-\mathrm{FDG}$ uptake on
PET/CT with ischemic vascular brain disease on MRI in patients with carotid artery disease. Ann Nucl Med 2019;33:907-15.

90. Tönnis W, Schiefer W. Physiologie und Pathophysiologie der Hirndurchblutung. Zirkulationsstörungen des Gehirns im Serienangiogramm. Springer, 1959:49-65.

91. Zülch KJ. The Cerebral Infarct. Berlin: Springer Verlag, 1985.

92. van der Zwan A, Hillen B, Tulleken CAF, et al. Variability of the territories of the major cerebral arteries. J Neurosurg 1992;77:927-40.

93. van Laar PJ, Hendrikse J, Golay X, et al. In vivo flow territory mapping of major brain feeding arteries. NeuroImage 2006;29:136-44.

94. van Laar PJ, Hendrikse J, Klijn CJM, et al. Symptomatic Carotid Artery Occlusion: Flow Territories of Major Brain-Feeding Arteries. Radiology 2007;242:526-34.

95. Kaczmarz S, Griese V, Preibisch C, et al. Increased variability of watershed areas in patients with high-grade carotid stenosis. Neuroradiology 2018;60:311-23.

96. Richter V, Helle M, van Osch MJP, et al. MR Imaging of Individual Perfusion Reorganization Using Superselective Pseudocontinuous Arterial Spin-Labeling in Patients with Complex Extracranial Steno-Occlusive Disease. AJNR Am J Neuroradiol 2017;38:703-11.

97. Bogousslavsky J, Regli F. Unilateral watershed cerebral infarcts. Neurology 1986;36:373.

98. Jörgensen L, Torvik A. Ischaemic cerebrovascular diseases in an autopsy series Part 2. Prevalence, location, pathogenesis, and clinical course of cerebral infarcts. J Neurol Sci 1969;9:285-320.

99. Ringelstein EB, Zeumer H, Angelou D. The pathogenesis of strokes from internal carotid artery occlusion. Diagnostic and therapeutical implications. Stroke 1983;14:867-75.

100. Wodarz R. Watershed infarctions and computed tomography. A topographical study in cases with stenosis or occlusion of the carotid artery. Neuroradiology 1980;19:245-8.

101. Yong SW, Bang OY, Lee PH, et al. Internal and Cortical Border-Zone Infarction: Clinical and Diffusion-Weighted Imaging Features. Stroke 2006;37:841-6.

102. Mangla R, Kolar B, Almast J, et al. Border Zone Infarcts: Pathophysiologic and Imaging Characteristics. RadioGraphics 2011;31:1201-4.

103. Bladin CF, Chambers BR. Frequency and pathogenesis of hemodynamic stroke. Stroke 1994;25:2179-82.

104. Gottesman RF, Sherman PM, Grega MA, et al. Watershed 
Strokes After Cardiac Surgery: Diagnosis, Etiology, and Outcome. Stroke 2006;37:2306-11.

105. Kaczmarz S, Göttler J, Petr J, et al. Hemodynamic impairments within individual watershed areas in asymptomatic carotid artery stenosis by multimodal MRI. J Cereb Blood Flow Metab 2021;41:380-96.

106. Wiart M, Berthezène $Y$, Adeleine $P$, et al. Vasodilatory Response of Border Zones to Acetazolamide Before and After Endarterectomy: An Echo Planar Imaging-Dynamic Susceptibility Contrast-Enhanced MRI Study in Patients With High-Grade Unilateral Internal Carotid Artery Stenosis. Stroke 2000;31:1561-5.

107.Leblanc R, Lucas Yamamoto Y, Tyler JL, et al. Borderzone ischemia. Ann Neurol 1987;22:707-13.

108. Mull M, Schwarz M, Thron A. Cerebral Hemispheric Low-Flow Infarcts in Arterial Occlusive Disease: Lesion Patterns and Angiomorphological Conditions. Stroke 1997;28:118-23.

109. Rodda RA. The arterial patterns associated with internal carotid disease and cerebral infarcts. Stroke 1986;17:69-75.

110. Schomer DF, Marks MP, Steinberg GK, et al. The Anatomy of the Posterior Communicating Artery as a Risk Factor for Ischemic Cerebral Infarction. N Engl J Med 1994;330:1565-70.

111. Weill C, Suissa L, Darcourt J, et al. The Pathophysiology of Watershed Infarction: A Three-Dimensional Time-ofFlight Magnetic Resonance Angiography Study. Journal of Stroke and Cerebrovascular Diseases 2017;26:1966-73.

112. Sorgun MH, Rzayev S, Yilmaz V, et al. Etiologic Subtypes of Watershed Infarcts. Journal of Stroke and Cerebrovascular Diseases 2015;24:2478-83.

113. Beal MF, Williams RS, Richardson EP, et al. Cholesterol embolism as a cause of transient ischemic attacks and cerebral infarction. Neurology 1981;31:860.

114. Masuda J, Yutani C, Ogata J, et al. Atheromatous embolism in the brain: A clinicopathologic analysis of 15 autopsy cases. Neurology 1994;44:1231.

Cite this article as: Mechtouff L, Rascle L, Crespy V, Canet-Soulas E, Nighoghossian N, Millon A. A narrative review of the pathophysiology of ischemic stroke in carotid plaques: a distinction versus a compromise between hemodynamic and embolic mechanism. Ann Transl Med 2021;9(14):1208. doi: 10.21037/atm-20-7490
115.Pollanen MS, Deck JH. Directed embolization is an alternate cause of cerebral watershed infarction. Arch Pathol Lab Med 1989;113:1139-41.

116. Torvik A, Skullerud K. Watershed infarcts in the brain caused by microemboli. Clin Neuropathol 1982;1:99-105.

117.Pollanen MS, Deck JHN. The Mechanism of Embolic Watershed Infarction: Experimental Studies. Can j neurol sci 1990;17:395-8.

118. Tsukada N, Katsumata M, Oki K, et al. Diameter of fluorescent microspheres determines their distribution throughout the cortical watershed area in mice. Brain Research 2018;1679:109-15.

119. Maki T, Wakita H, Mase M, et al. Watershed infarcts in a multiple microembolic model of monkey. Neuroscience Letters 2011;499:80-3.

120.Liberman AL, Zandieh A, Loomis C, et al. Symptomatic Carotid Occlusion Is Frequently Associated With Microembolization. Stroke 2017;48:394-9.

121.Isabel C, Lecler A, Turc G, et al. Relationship between Watershed Infarcts and Recent Intra Plaque Haemorrhage in Carotid Atherosclerotic Plaque. PLoS One 2014;9:e108712.

122. Caplan LR, Hennerici M. Impaired Clearance of Emboli (Washout) Is an Important Link Between Hypoperfusion, Embolism, and Ischemic Stroke. Arch Neurol 1998;55:1475.

123.Moustafa RR, Momjian-Mayor I, Jones PS, et al. Microembolism Versus Hemodynamic Impairment in Rosary-Like Deep Watershed Infarcts: A Combined Positron Emission Tomography and Transcranial Doppler Study. Stroke 2011;42:3138-43.

124. Chongruksut W, Vaniyapong T, Rerkasem K. Routine or selective carotid artery shunting for carotid endarterectomy (and different methods of monitoring in selective shunting). Cochrane Database Syst Rev 2014;2014:CD000190. 